University of Nebraska - Lincoln

DigitalCommons@University of Nebraska - Lincoln

Publications from USDA-ARS / UNL Faculty

U.S. Department of Agriculture: Agricultural

Research Service, Lincoln, Nebraska

2015

\title{
Clonal integration in Ludwigia hexapetala under different light regimes
}

\author{
Rachael Glover \\ Biology Department, John Carroll University; USDA-Agricultural Research Service, Exotic \& Invasive Weeds \\ Research Unit, Department of Plant Sciences MS-4, University of California \\ Rebecca E. Drenovsky \\ Biology Department, John Carroll University, University Heights \\ Caryn J. Futrell \\ USDA-Agricultural Research Service, Exotic \& Invasive Weeds Research Unit, Department of Plant \\ Sciences MS-4, University of California \\ Brenda J. Grewell \\ USDA-Agricultural Research Service, Exotic \& Invasive Weeds Research Unit, Department of Plant \\ Sciences MS-4, University of California, bjgrewell@ucdavis.edu
}

Follow this and additional works at: https://digitalcommons.unl.edu/usdaarsfacpub

Part of the Other Environmental Sciences Commons

Glover, Rachael; Drenovsky, Rebecca E.; Futrell, Caryn J.; and Grewell, Brenda J., "Clonal integration in Ludwigia hexapetala under different light regimes" (2015). Publications from USDA-ARS / UNL Faculty. 1502.

https://digitalcommons.unl.edu/usdaarsfacpub/1502

This Article is brought to you for free and open access by the U.S. Department of Agriculture: Agricultural Research Service, Lincoln, Nebraska at DigitalCommons@University of Nebraska - Lincoln. It has been accepted for inclusion in Publications from USDA-ARS / UNL Faculty by an authorized administrator of DigitalCommons@University of Nebraska - Lincoln. 


\title{
Clonal integration in Ludwigia hexapetala under different light regimes
}

\author{
Rachael Glover $^{\mathrm{a}, \mathrm{b}}$, Rebecca E. Drenovsky ${ }^{\mathrm{a}}$, Caryn J. Futrell ${ }^{\mathrm{b}}$, Brenda J. Grewell ${ }^{\mathrm{b}, *}$ \\ a Biology Department, John Carroll University, University Heights, OH 44118-4581, United States \\ b USDA-Agricultural Research Service, Exotic \& Invasive Weeds Research Unit, Department of Plant Sciences MS-4, University of California, Davis, CA 95616, \\ United States
}

\section{A R T I C L E I N F O}

\section{Article history:}

Received 10 September 2014

Received in revised form 13 January 2015

Accepted 14 January 2015

Available online 20 January 2015

\section{Keywords:}

Clonal plants

Physiological integration

Resource sharing

Environmental heterogeneity

Invasive aquatic plant

Ludwigia

\begin{abstract}
A B S T R A C T
Physiological integration among ramets of invasive plant species may support their colonization and spread in novel aquatic environments where growth-limiting resources are spatially heterogeneous. Under contrasting light conditions, we investigated how clonal integration influences growth, biomass allocation and morphology of Ludwigia hexapetala, an emergent floating-leaved macrophyte that is highly invasive in a range of wetland habitat types. In aquatic mesocosms, stolons of offspring ramets were either connected or severed from parent plants, with the pairs exposed to homogenous or heterogeneous combinations of sun or $85 \%$ shade. Morphological traits of all ramets were strongly influenced by light environment, and low light availability decreased plant growth, regardless of integration status. Allocation patterns varied with light regime; shaded plants increased allocation to leaf biomass while sun plants allocated more resources to belowground growth. Offspring ramets integrated with parents produced more biomass, suggesting a fitness advantage through integration. However, parent ramet performance declined with stoloniferous integration; integrated parents produced fewer ramets and allocated more resources to belowground biomass. For most response variables measured, there was no significant interactive effect between light treatment and integration, although parents growing in the shade attached to an offspring in the sun increased root mass ratio. The ability to establish and spread into new environments is a key trait of invasive plants, and physiological integration of resources may improve the establishment of juvenile ramets across variable light environments during early colonization. Physiological integration in patchy light environments may contribute to the invasiveness of L. hexapetala.
\end{abstract}

Published by Elsevier B.V.

\section{Introduction}

Clonality is a common growth pattern and asexual reproductive strategy of aquatic plants, facilitating their rapid dispersal and colonization throughout watersheds (Pyšek and Prach, 1993; Santamaría, 2002). Across spatially heterogeneous environments, clonal plants can share nutrients, carbohydrates, and water through physiological integration of connected ramets (Alpert and Mooney, 1986). This flexibility in growth form provides many benefits to clonal plants, including improved ability to grow and colonize in low resource environments (Stuefer et al., 1994; Alpert, 1996). Under severe growing conditions or high environmental variability, clonal plants may have increased survivorship (Xu et al., 2010) because clones can respond plastically by dividing labor and sharing resources (Alpert, 1996, 1999a,b; Xiao et al., 2007). However,

\footnotetext{
* Corresponding author. Tel.: +1 5307520166.

E-mail address: bjgrewell@ucdavis.edu (B.J. Grewell).
}

the benefits of clonal integration among ramets can vary among wetland plant species (Pennings and Callaway, 2000). Clonal integration also incurs maintenance costs related to stolon tissue, loss of internal resources due to resource sharing, and high genet or ramet mortality (Jónsdóttir and Watson, 1997). Under homogeneous conditions, clonal integration may be disadvantageous because the cost of the connection outweighs the resources gained (Alpert et al., 2003).

Light is a key resource that can be spatially heterogeneous, and thus may influence the growth and development of clonal plants. Floating-leaved species of macrophytes are the most competitive for light relative to other functional groups of aquatic plants and can dominate plant communities when nutrient availability and turbidity in the water column are high (Bornette and Puijalon, 2011). In shade, aquatic plants experience both decreased light quantity and quality (Méthy et al., 1990). Whereas the quantity of light in the environment supports plant growth, light quality has more influence on the morphology of plant leaves (Gratani, 2014). Clonal growth may be favored in heterogeneous light 
conditions, because rhizome or stolon production may help plants avoid the stress of limited light by directing ramet growth toward regions with more light (Méthy et al., 1990), potentially allowing resource sharing with clones growing in low light. In integration experiments with Fragaria chiloensis (L.) Duchesne in sand dunes, light deficient clones connected to ramets with access to sunlight accumulated more biomass than ramets in homogeneous high or low light conditions (Stuefer et al., 1994; Alpert, 1999a). Similarly, the aquatic plant Alternanthera philoxeroides (Martius) Grisebach shared resources between ramets growing in the sun and in the shade, and connection with an unshaded ramet improved establishment success of new ramets (Xu et al., 2012).

Due to the potential benefits that clonal growth has on plant establishment and spread, particularly in patchy or low resource environments, clonality may promote colonization of novel habitats by invasive plant species. Because of prolific ramet production and its positive impacts on survivorship (Barrat-Segretain et al., 1998), clonal growth may be favored in areas of high disturbance (Grace, 1993). In fact, non-native and invasive plants are more likely to be clonal than native plants, as clonal plants are more successful at expanding outside of their native range than non-clonal species (Thompson et al., 1995).

Surprisingly little research has focused on the benefits of clonal integration for aquatic invasive weeds (see Xiao et al., 2007, 2011). Aquatic systems are prone to disturbance events, such as flooding, which may provide gaps in the riparian zone for rapidly establishing species (Pyšek and Prach, 1993). Additionally, patchy resource availability in aquatic environments (Santamaría, 2002) may favor species with weedy, ruderal growth (Grime, 1977). Thus, clonal growth may be beneficial as a means of resource acquisition and rapid dispersal. For example, light availability along waterways and in riparian zones can be patchy (Gregory et al., 1991), and the success of non-native, clonal species in these environments may be linked to their ability to successfully forage for light and share resources.

In this study, we investigated the effect of clonal integration on ramets of Ludwigia hexapetala (Hook \& Arn) Zardini, H. Gu \& P.H. Raven (Onagraceae: syn. L. grandiflora ssp. hexapetala, Wagner et al., 2007) in contrasting light environments. L. hexapetala is a perennial, emergent floating-leaved aquatic plant native to South America that forms dense, buoyant mats over the water surface. Introduced as an ornamental plant, it has long been an invasive species in France, and more recently it has invaded watersheds elsewhere in Europe and in the United States (Thouvenot et al., 2013b). The primary mode of spread is hydrochorous dispersal of floating asexual shoot fragments, although the species also reproduces sexually via buoyant fruit capsules with viable seeds (Okada et al., 2009). Dispersal of rhizome fragments by hydrochory following bank erosion events is also possible, but not common. This flexible species has colonized a wide range of wetland habitats in both the native and invasive range and appears to tolerate both aquatic and seasonally wet environments (Thouvenot et al., 2013b).

Experiments suggest the quantity of sunlight available to $L$. hexapetala plays a dominant role in its growth, biomass production, and invasion success (Thouvenot et al., 2013a). It is possible that light heterogeneity along the river edge makes the riparian zones a suitable habitat for clonal species such as $L$. hexapetala, promoting its spread, as its ability to grow both stoloniferously and rhizomatously may encourage resource sharing among clones. Currently, there is no known study on clonal integration in response to light availability with $L$. hexapetala, and little is known about its sensitivity to light and how clones respond to reduced light in shaded habitats. This information could be useful in understanding the growth and morphology of $L$. hexapetala and in the development of control mechanisms for this and other invasive aquatic clonal plants.
This study addressed two questions: (1) Does low light decrease plant performance in the clonal aquatic plant $L$. hexapetala? and (2) How does clonal integration influence plant performance under differing light environments? We hypothesized that low light availability would decrease plant performance, regardless of the target plant's integration status. Second, we predicted that offspring performance, regardless of light environment, would increase when integrated with a parent ramet. In contrast, parent ramets, regardless of light environment, would be negatively impacted by integration with an offspring ramet. Third, we hypothesized that the relative benefit or cost of integration, for either offspring or parent ramets, would depend on whether the light environment was homogenous or heterogeneous.

\section{Materials and methods}

\subsection{Experimental design}

Source material of $L$. hexapetala for experimental treatments was collected from a $2 \mathrm{~km}$ reach of the Russian River near Asti, California, USA ( $\left.38^{\circ} .764-122^{\circ} .968\right)$. Forty-five, $1.5 \mathrm{~m}$ long clippings of L. hexapetala were taken approximately $5-10 \mathrm{~m}$ apart in the river and transported on ice to the USDA-ARS Aquatic Weed Research Facility at the University of California, Davis. Cuttings were placed in deionized water in shallow plastic tubs indoors until transplanting $(<48 \mathrm{~h})$. Ramets were planted in pots $(19.5 \mathrm{~cm}$ height, $14 \mathrm{~cm}$ inner diameter) with a modified University of California soil mix (described in Spencer and Anderson, 1986) containing a 50:50 ratio of sand to topsoil, micronutrients, and $15 \mathrm{~g}$ of Osmocote ${ }^{\circledR}$ slow release fertilizer (Scotts Miracle Grow Co., Marysville, Ohio, USA) with $0.17 \% \mathrm{~N}, 0.027 \% \mathrm{P}$, and $0.0036 \% \mathrm{~K}$ per pot. Pots were placed in 75 L plastic mesocosms (Utilatub, Model 14, Cleveland, Ohio, USA) containing approximately $70 \mathrm{~L}$ of deionized water. Mesocosms were paired, allowing connection between ramets for integrated treatments (Fig. 1). The clipped stem was buried in the soil 21 nodes from the apical tip and was considered the parent plant. The offspring plant was rooted 9 nodes from the buried end of the parent plant using an $8.8 \mathrm{~cm}$ galvanized wire support stake to secure it in the soil mix. Consequently, the offspring plant contained the apical meristem. Growmore ${ }^{\circledR}$ Eco Pond Clear (organic bacterial product, Growmore Inc., Gardena, California, USA) was added to mesocosms every other day to control potential algal growth, and water levels were maintained by replacing evaporated water in the mesocosms every 2-3 days. Plants were allowed to establish for 5 days prior to treatment initiation.

In order to understand how integration influences clonal plants under different light regimes, 6 replicates of 2 target $L$. hexapetala plants (parent and offspring) were randomly assigned to one of three different light treatments (Sun/Sun Shade/Shade, Shade/Sun) and one of two integration treatments (integrated or severed). In the treatments, both ramets were in ambient light (Sun/Sun), both

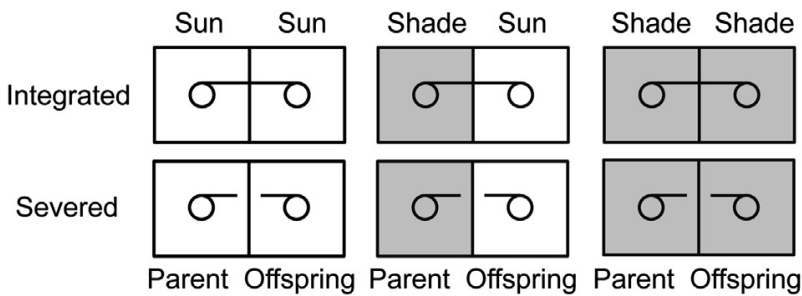

Fig. 1. One replicate of the experimental design, where the squares represent the water-filled tubs in which pots (circles) were placed. Each pair of squares consists of one experimental parent/offspring unit subjected to one of three light treatment combinations (Sun/Sun Shade/Sun; Shade/Shade) and with the ramet connection either integrated (solid line) or severed (broken line). 
ramets were shaded (Shade/Shade), or the offspring was in ambient light and the parent was shaded (Shade/Sun). Due to limited availability of mesocosms, a full factorial design was not possible. Therefore, a Sun/Shade treatment was omitted because $L$. hexapetala ramets typically do not grow from sun toward shade in field conditions (Grewell, personal obs.). Following light treatment initiation, ramets were allowed to grow for an additional week before initiating integration treatments. After one week, the stolon between parent ramets and offspring ramets was artificially severed in half of the pairs to prevent sharing of resources ('severed treatment'); the other half were left connected ('integrated treatment').

The shaded treatments were created using shade structures with $80 \%$ shade cloth that were secured to the mesocosms. Following treatment initiation, light levels were measured in both treatments using a Licor LI-250A light meter (LICOR Inc., Lincoln, Nebraska, USA) and were repeated weekly at solar noon $(11: 00-12: 00 \mathrm{~h})$. The average light levels in the open were $2029.1 \pm 1.7 \mu \mathrm{mol} \mathrm{m}^{-2} \mathrm{~s}^{-1}$ (mean \pm S.E.) while the average light levels under the shade structures were $301.8 \pm 1.7 \mu \mathrm{mol} \mathrm{m}^{-2} \mathrm{~s}^{-1}$ (mean \pm S.E.). Therefore, the $80 \%$ shade cloth reduced light to $\sim 15 \%$ of ambient. The shade panels were only $3 / 4$-length on the east side of the tubs and completely open on the north side of the tubs, allowing proper air-flow and maintaining ambient humidity within the shade structures. Humidity sensors indicated differences in relative humidity between light treatments were minimal ( $\approx 2 \%$ difference). Plants were grown under their respective light regimes for 1 month (June 18-July 14, 2012) before harvest, to prevent the plants from outgrowing their mesocosms and causing crowding effects.

Water temperature was recorded hourly using Stowaway TidbiT Temperature Data Loggers (TB132, Onset Computer Corp., Pocasset, Massachusetts, USA). Differences in water temperature averaged $4.4^{\circ} \mathrm{C}$ between sun and shade treatments during daylight hours (maximum difference recorded was $8.3^{\circ} \mathrm{C}$ in late afternoon), while there were no differences in night temperatures among treatments.

\subsection{Plant morphological traits}

Upon harvest, primary (longest) stem length (for offspring plants with apical tips) and length of the longest branch (parents, without apical tips), as well as total number of rooting stem nodes, branches, and leaves were measured. For dry mass and biomass allocation, shoots were separated from the roots at the soil surface, and the soil was sieved to obtain all fine belowground roots. Biomass allocation was measured as root mass ratio (RMR, root mass/total biomass; \%), specific leaf area (SLA, leaf area/leaf mass; $\mathrm{m}^{2} \mathrm{~kg}^{-1}$ ), and leaf mass ratio (LMR, leaf mass/total biomass; \%). Total leaf area and average leaf length and width were analyzed via image analysis (WinFolia 2009a, Regent Instruments, Canada). Following image analysis, leaves were dried with the other biomass in the oven at $70{ }^{\circ} \mathrm{C}$ for approximately $48 \mathrm{~h}$.

\subsection{Statistical analyses}

We assessed the significance of treatment effects and interactive effects with a two way ANOVA (GLM procedure, SAS, v 9.2, SAS Institute Inc.). Our ANOVA model had two main effects (light, integration) and one interaction term (light $\times$ integration) for each response variable. We used a threshold value of $p<0.05$ to consider significance of individual responses and their interactions. The light treatments were paired so that there were three treatment levels: Sun/Sun (SuSu), Shade/Shade (ShSh), or Shade/Sun (ShSu). Integration had two treatment levels (severed (S), integrated (I)). We tested normality and equal variance using the Shapiro Wilks test and Levene's test, respectively. Only leaf length and leaf width in offspring plants did not meet the assumptions of normality and

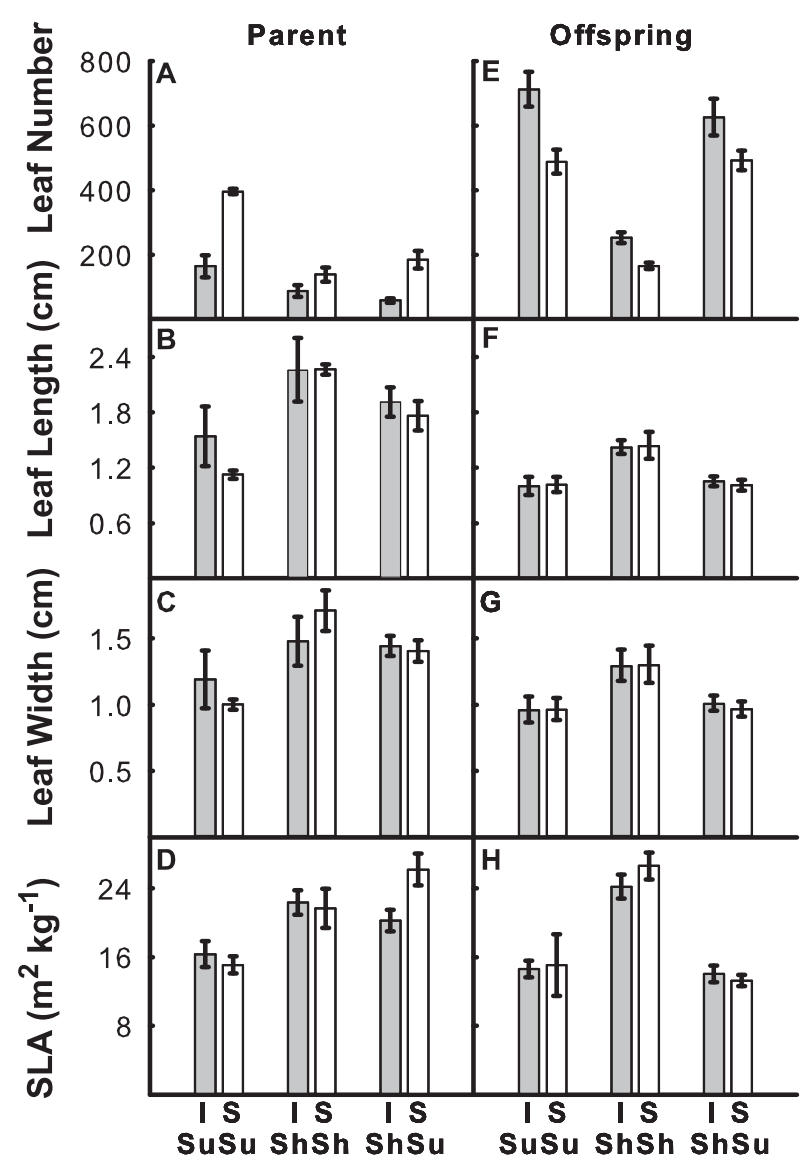

Fig. 2. Leaf number ( $A$ and $E$ ), leaf length (B and $F$ ), leaf width ( $C$ and $G$ ) and specific leaf area (D and $\mathrm{H}$ ) of parent (left) and offspring plants (right) of Ludwigia hexapetala that were integrated (I) or severed (S). Data for leaf length and leaf width are mean \pm standard error $(n=4)$. The rest of the panels are means \pm standard error $(n=6)$. Abbreviations include Su (sun), Sh (shade), I (integrated), and S (severed).

were log transformed. Leaf number, number of rooted stem nodes, and stolon length in offspring plants and RMR in parent plants did not meet the assumption of equal variance and their sums of squares were weighted by the inverse variance.

\section{Results}

\subsection{Morphological traits}

Morphological traits in parent ramets were strongly impacted by light treatment. Across light treatments, leaf number, branch number, and rooting node number varied $2.5,3.1$, and 1.9 -fold, respectively, with counts always greatest in high light treatments (Su/Su) when compared to low light (Sh/Sh) (Fig. 2A, Fig. 3A and B, Table 1). Shade leaves were longer, wider, and thinner (estimated by SLA) than sun leaves in parent plants, varying $1.7,1.5$, and 1.5fold, respectively, across light treatments (Fig 2B-D, Table 1). Light treatment also had a significant impact on all morphological traits measured in offspring plants. Leaf number, branch number, and rooting node number varied $\approx 2.9,3.1$, and 1.9 -fold, respectively, where count values were always higher for offspring experiencing high light treatments (Fig. 2E, Fig. 3E and F, Table 1). Light availability also influenced leaf morphology in offspring ramets. Leaf length, width, and thickness varied 2.2, 2.0, and 1.5-fold across light treatments, with longer, wider, and thinner leaves produced by shaded offspring (Fig. 2F-H, Table 1).

In general, parent plants did not benefit from stoloniferous integration with their offspring ramets. When severed from their 
Table 1

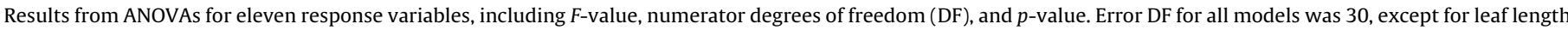
and width, where error DF was 18. Bold type indicates $p<0.05$.

\begin{tabular}{|c|c|c|c|c|c|c|c|}
\hline & \multirow[b]{2}{*}{ Model effect } & \multicolumn{3}{|l|}{ Parent } & \multicolumn{3}{|c|}{ Offspring } \\
\hline & & $F$ & DF & $p$ & $F$ & $\mathrm{DF}$ & $p$ \\
\hline \multirow[t]{3}{*}{ Leaf number } & Light & 36.9 & 2 & $<0.0001$ & 114.3 & 2 & $<0.0001$ \\
\hline & Integration & 57.9 & 1 & $<0.0001$ & 24.4 & 1 & $<0.0001$ \\
\hline & Light $\times$ integration & 8.5 & 2 & 0.001 & 2.0 & 2 & 0.157 \\
\hline \multirow[t]{3}{*}{ Branch number } & Light & 18.9 & 2 & $<0.0001$ & 84.1 & 2 & $<0.0001$ \\
\hline & Integration & 14.8 & 1 & 0.0006 & 30.0 & 1 & $<0.0001$ \\
\hline & Light $\times$ integration & 1.8 & 2 & 0.178 & 2.8 & 2 & 0.078 \\
\hline \multirow[t]{3}{*}{ Rooting nodes } & Light & 14.6 & 2 & $<0.0001$ & 43.2 & 2 & $<0.0001$ \\
\hline & Integration & 65.2 & 1 & $<0.0001$ & 50.6 & 1 & $<0.0001$ \\
\hline & Light $\times$ integration & 1.7 & 2 & 0.201 & 3.8 & 2 & 0.034 \\
\hline \multirow[t]{3}{*}{ Leaf length } & Light & 9.4 & 2 & 0.002 & 134.7 & 2 & $<0.0001$ \\
\hline & Integration & 1.1 & 1 & 0.306 & 0.08 & 1 & 0.782 \\
\hline & Light $\times$ integration & 0.48 & 2 & 0.624 & 0.90 & 2 & 0.424 \\
\hline \multirow[t]{3}{*}{ Leaf width } & Light & 6.5 & 2 & 0.008 & 74.5 & 2 & $<0.0001$ \\
\hline & Integration & 0.0 & 1 & 0.989 & 0.25 & 1 & 0.626 \\
\hline & Light $\times$ integration & 1.2 & 2 & 0.335 & 0.55 & 2 & 0.589 \\
\hline \multirow[t]{3}{*}{ Specific leaf area } & Light & 12.6 & 2 & 0.0001 & 25.7 & 2 & $<0.0001$ \\
\hline & Integration & 1.1 & 1 & 0.313 & 0.22 & 1 & 0.642 \\
\hline & Light $\times$ integration & 3.1 & 2 & 0.060 & 0.40 & 2 & 0.675 \\
\hline \multirow[t]{3}{*}{ Stolon length } & Light & 16.0 & 2 & $<0.0001$ & 30.0 & 2 & $<0.0001$ \\
\hline & Integration & 41.1 & 1 & $<0.0001$ & 2.9 & 1 & 0.102 \\
\hline & Light $\times$ integration & 3.1 & 2 & 0.058 & 0.72 & 2 & 0.493 \\
\hline \multirow[t]{3}{*}{ Internode length } & Light & 4.5 & 2 & 0.020 & 8.8 & 2 & 0.001 \\
\hline & Integration & 30.3 & 1 & $<0.0001$ & 0.37 & 1 & 0.547 \\
\hline & Light $\times$ integration & 1.0 & 2 & 0.369 & 0.44 & 2 & 0.650 \\
\hline \multirow[t]{3}{*}{ Total biomass } & Light & 11.9 & 2 & 0.0002 & 49.2 & 2 & $<0.0001$ \\
\hline & Integration & 19.8 & 1 & 0.0001 & 4.6 & 1 & 0.040 \\
\hline & Light $\times$ integration & 3.5 & 2 & 0.043 & 0.60 & 2 & 0.556 \\
\hline \multirow[t]{3}{*}{ Leaf mass ratio } & Light & 16.6 & 2 & $<0.0001$ & 42.0 & 2 & $<0.0001$ \\
\hline & Integration & 21.8 & 1 & $<0.0001$ & 0.62 & 1 & 0.439 \\
\hline & Light $\times$ integration & 2.5 & 2 & 0.100 & 0.28 & 2 & 0.756 \\
\hline \multirow[t]{3}{*}{ Root mass ratio } & Light & 11.1 & 2 & 0.0003 & 19.0 & 2 & $<0.0001$ \\
\hline & Integration & 8.0 & 1 & 0.0081 & 2.3 & 1 & 0.142 \\
\hline & Light $\times$ integration & 5.1 & 2 & 0.012 & 1.2 & 2 & 0.306 \\
\hline
\end{tabular}

offspring, parents produced $\approx 2.3,2.0$, and 2.5 -fold greater number of leaves, branches, and rooted stem nodes (Fig. 2A, Fig. 3A and $B$, Table 1 ). Leaf length, width, and thickness were not significantly affected by integration status (Table 1). Although none of the plants in the sun produced flower buds, some of the parent and offspring plants in the shade produced a few flower buds, especially when integrated with another shaded plant (data not shown). The only morphological trait that showed a significant light treatment $\times$ integration interaction was leaf number (Fig. 2A, Table 1). Although severed parent plants always produced more leaves than integrated parent plants, leaf number was highest in severed parent plants growing in the sun. All other parent morphological traits showed no significant light treatment $\times$ integration interaction (Table 1). Offspring generally benefitted from being integrated with their parent plant. Offspring had 1.4 times more leaves, 1.4 times more branches, and 1.5 times more rooting nodes than offspring severed from their parent (Fig. 2E, Fig. 3E and F, Table 1). However, leaf length, width, and thickness did not vary based on integration (Table 1). The only morphological trait that showed a significant light treatment $\times$ integration interaction was the number of rooting nodes (Fig. 3F, Table 1). Although offspring ramets always produced more rooting nodes when integrated with its parent plant, the magnitude of the difference between integrated and severed treatments for rooting nodes was greatest for offspring plants growing in the sun.

\subsection{Growth and allocation}

Similar to morphological responses, plant growth and allocation was strongly influenced by light treatment. Across light treatments, stolon length and internode length of parent plants varied 1.9 and 1.3-fold, respectively, with parents in the sun growing longer stolons with longer internodes (Fig. $3 \mathrm{C}$ and D, Table 1 ). Light treatment impacted total biomass in parent plants (Fig 4A, Table 1), with parents in the sun having 1.6 times higher total biomass than parents in the shade. Light availability also influenced allocation to leaves versus roots, with a 1.7 -fold increase in LMR in the shade treatment and a 1.2-fold increase in RMR in the sun treatment (Fig. 4B and C, Table 1). Similar to parent plants, stolon and internode length of offspring plants varied $\approx 1.6$ and 1.3 -fold, respectively, among light treatments. Offspring in high light generally grew longer stolons with longer internodes (Fig. 3G and H, Table 1). Total biomass of the offspring was impacted by light treatment (Fig. 4D, Table 1), with offspring in the sun having 2.2 times higher total biomass than offspring in the shade. LMR was 1.7-fold higher in the shade treatment and RMR was 1.4-fold higher in the sun treatment (Fig. 4E and F, Table 1). In general, plants in the shade allocated more to leaf biomass and area than to root mass. In contrast to light availability, integration had no significant effect on any of the growth or allocation traits measured in offspring ramets (Table 1 ), except for total biomass, in which integrated offspring had slightly higher 


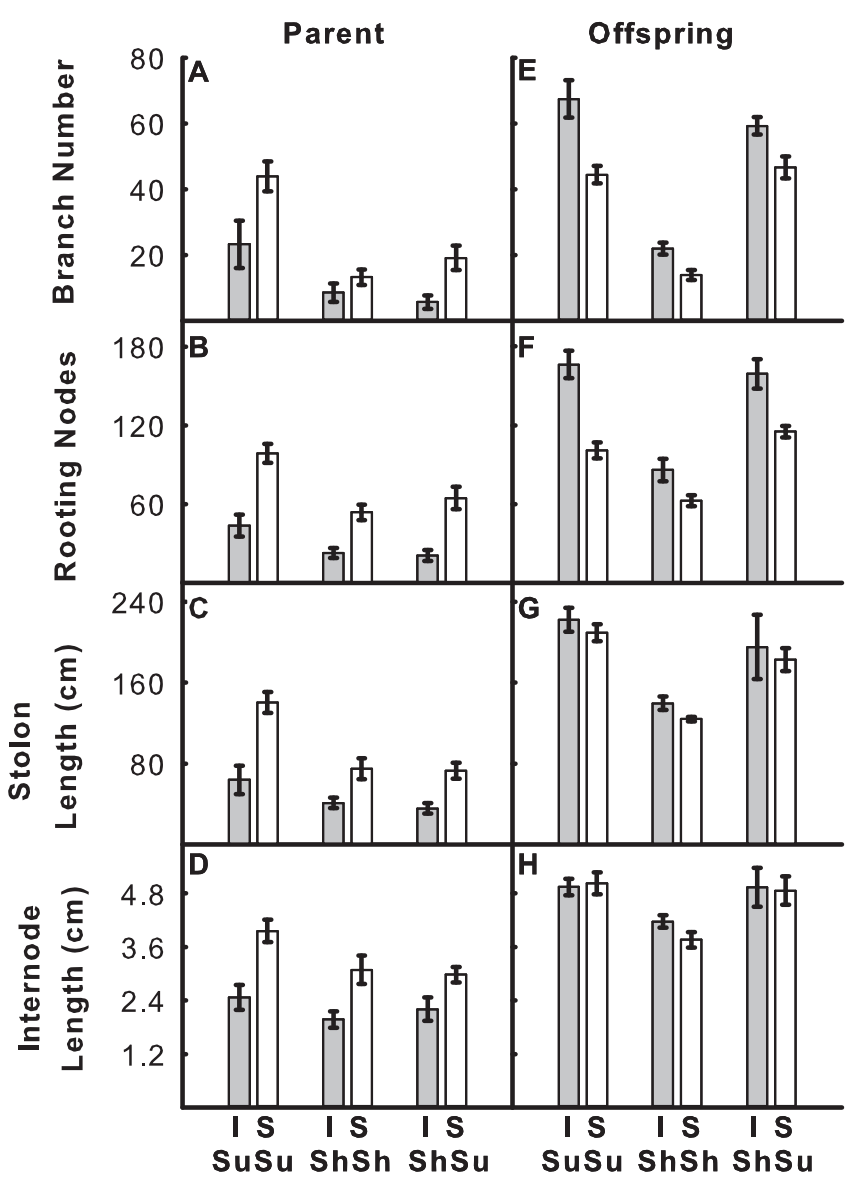

Fig. 3. Branch number ( $A$ and $E$ ), number of rooting nodes (B and $F$ ), stolon length (C and $\mathrm{G}$ ) and internode length (D and $\mathrm{H}$ ) in parent (left) and offspring plants (right) of Ludwigia hexapetala that were integrated (I) or severed (S). Abbreviations include $\mathrm{Su}$ (sun), Sh (shade), I (integrated), and S (severed). Data are means \pm standard error $(n=6)$.

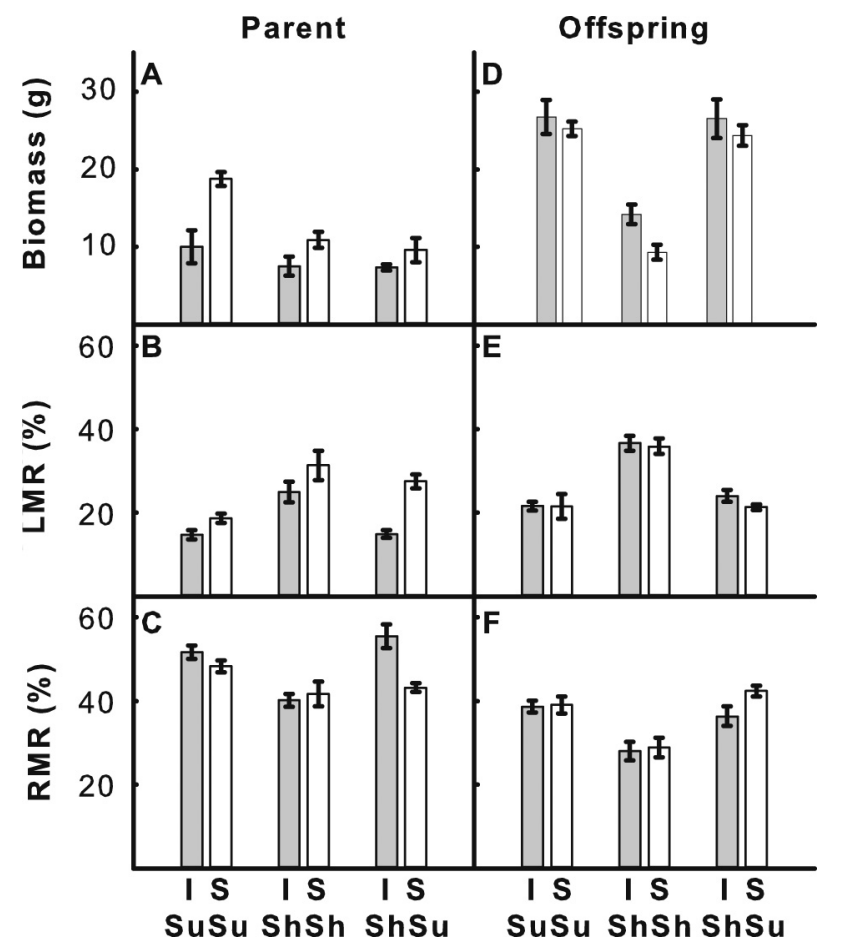

Fig. 4. Total biomass in parent (A) and offspring plants (D) of Ludwigia hexapetala that were integrated (I) or severed (S). Leaf mass ratio (LMR) and root mass ratio (RMR) are abbreviated. Data are means \pm standard error $(n=6)$. total biomass than severed offspring (Fig. 4D, Table 1). Likewise, there was no significant light treatment $\times$ integration interaction effects for these variables (Table 1 ).

Unlike offspring plants in which few of the growth and allocation traits were impacted by integration status (Table 1), growth and allocation in parents was significantly influenced by integration. Severed parents had 1.5 and 1.2 times longer internodes and stolons (Fig 3C and D, Table 1) and allocated 1.4 times more biomass to leaves and 1.1 times less biomass to roots (Fig $4 \mathrm{~B}$ and C, Table 1) than integrated parents. In general, integration also impacted total biomass in parent plants (Fig. 4A, Table 1), in which severed parents had 1.5 times higher total biomass than integrated parents. There was a significant interaction between light treatment and integration for total biomass and RMR (Table 1) in parent plants. RMR was similar between integrated and severed parent plants in most light environments; however, shaded integrated parents tended to invest more biomass in roots when attached to daughter plants in the sun (Fig. 3).

\section{Discussion}

Low light availability decreased growth of $L$. hexapetala regardless of the target plant's integration status. In shaded conditions, lateral branching and stolon growth of plants are typically reduced, as more resources are allocated to leaves rather than shoot growth (Riis et al., 2012). L. hexapetala in shade had shorter stolons, and fewer leaves, branches and rooting nodes than plants in sun. Counter to expectations, internode length also increased in sun plants. Increased internode length was also noted for $A$. philoxeroides in sun and may reflect a higher growth rate and competitive ability (Xu et al., 2012). In L. hexapetala, the increase in internode length corresponded to differences in morphology between plants in shade versus plants in sun. In sun, stolons elongate rapidly and "creep" horizontally along the water surface (sensu Rejmánkova, 1992); in contrast, plants in shade grow more slowly with shoots growing vertically toward sunlight. Thus, increased internode lengths in sun plants may facilitate more rapid spread of $L$. hexapetala.

Allocation patterns also differed between light treatments. Plants in sun increased belowground biomass, whereas shaded plants increased aboveground biomass, as observed in other studies (Poorter et al., 2012; Riis et al., 2012). Reductions in belowground biomass and lateral branching are consistent with the foraging concept; shaded plants generally increase aboveground allocation and lateral spread to improve resource acquisition and reduce respiratory costs (de Kroon and Hutchings, 1995). In addition to increases in LMR, morphological changes to increase surface area of leaves in shade can promote more efficient light capture (Valladares and Niinemets, 2008). At harvest, plants in the shade were the only plants that produced flower buds. Shade environments can promote earlier shifts in phenology, as an effort to disperse offspring away to a more favorable light environment (Loehle, 1987), or to avoid resource costs associated with clonal integration (Jónsdóttir and Watson, 1997).

Regardless of light environment, we predicted offspring performance would increase when integrated with a parent ramet, but parent ramets would be negatively impacted by stoloniferous integration with an offspring ramet. Offspring that were integrated with their parents did have more leaves and increased lateral growth (branching) that could improve light capture for photosynthesis (Richards and Lee, 1986). They also had more rooting nodes and higher total biomass; both of which provide fitness benefits, as abundant fragments with rooting nodes can lead to establishment of newly dispersed, colonizing ramets (Okada et al., 2009).

In contrast, performance of parent plants declined under integration with offspring as indicated by decreased branching, leaf 
number, rooting nodes, stolon and internode lengths, leaf area, and LMR. These parent ramets also produced greater belowground biomass, suggesting either a greater resource acquisition demand to support offspring ramets or a shift to resource storage via rhizomes. Offspring ramets, in general, receive considerable parental resources benefitting their growth (Xu et al., 2010, 2012), and the direction of resource sharing tends to favor younger ramets (Alpert, 1996). Parent ramets may have translocated resources to offspring at the expense of their own shoot growth and development.

We predicted that response to light availability would be influenced by a plant's integration status. Specifically, the relative benefit or cost of stoloniferous integration, for either offspring or parent ramets, would depend on whether the light environment was homogenous or heterogeneous. For most response variables measured, an interactive effect between light treatment and integration was not detected. However, an increase in RMR of parents growing in the shade attached to an offspring in the sun was observed, suggesting a response to resource demand from the offspring plant. This growth pattern may promote carbon storage and the annual resprouting of $L$. hexapetala plants that often grow and perennate along shaded river banks. In spring, new growth of buoyant shoots initiates from shaded riparian areas, and they grow across the water surface, perpendicular to the shoreline to where more light is available (Grewell, personal obs.). Leaf production also increased when parents growing in shade were severed from offspring in sun. Once severed, the shaded parents increased leaf production and area, enhancing their ability to capture light in the shade. In contrast, $L$. hexapetala offspring in sun integrated with parents in sun produced the most rooting nodes, suggesting a fitness benefit when both ramets are in sun, since shoot fragments with rooted nodes should facilitate establishment of new offspring following hydrochory.

In contrast to previous studies (e.g., Alpert, 1999a; Xiao et al., 2007), our results offer little support for the hypothesis that plants growing in less optimal conditions benefit from being integrated with plants in optimal habitat. The limited integration effect could be because resource sharing depends on which ramet (parent or offspring) is located in a resource rich patch (Wolfer and Straile, 2012), or because of other factors not considered such as age of ramets or clonal growth form (Song et al., 2013 Xu et al., 2012). Our focus was on stoloniferous integration because aboveground biomass production of this species far exceeds that of belowground biomass (Grewell, unpublished data). However, in stressful environments this invasive species may actually rely more on stored resources or rhizomatous integration rather than stoloniferous translocation of resources as has been observed in the aquatic macrophyte $A$. philoxeroides (Xu et al., 2012). The potential direction of resource flow may also influence the impact of integration for plants in heterogeneous environments (Alpert and Mooney, 1986). Although not measured in this study, it is possible that photosynthetic resources are not shared between offspring and parent plants because offspring may be a stronger carbon sink than source due to active growth. The benefits of integration may also depend on the homogeneity or heterogeneity pattern of multiple resources such as light, water, and nutrients, rather than just one resource (He et al., 2011). Perhaps clonal integration is less beneficial if one ramet is located in a stressful environment and cannot contribute resources, as one of the major benefits of clonal growth in patchy environments is division of labor (Alpert, 1996, 1999a,b; Xiao et al., 2007).

Overall, light availability strongly impacted plant growth, biomass production and morphology in both parent and offspring ramets of $L$. hexapetala. Ramets in the shade foraged for light, shifting biomass allocation aboveground and increasing leaf surface area for light interception, regardless of integration status. Decreased light availability also shifted phenology, with ramets in the shade more rapidly producing flower buds, suggesting low light environments may promote an earlier switch to sexual reproduction and dispersal to new environments via seeds. However, the impacts of integration depended on target plant identity. Parent ramets did not benefit from integration. Integrated offspring ramets tended to produce more rooting nodes, particularly when attached to a parent plant in the sun, as well as greater total biomass than parents. The ability to establish and spread into new environments is a key trait of invasive plants, and understanding which factors promote these critical population parameters in L. hexapetala will help provide a framework for the development of successful management techniques. Our results suggest physiological integration in patchy light environments influences the growth of $L$. hexapetala, and therefore can contribute to its invasiveness.

\section{Acknowledgements}

We thank Elisabeth Gross, Jeffrey R. Johansen, Christopher Sheil, Meghan Skaer Thomason, and two anonymous reviewers for comments that improved this manuscript, and Meghan Skaer Thomason for assistance with analyses. Ben Bradford, Anna Dwyer, Juan Meija and Meghan Skaer Thomason assisted with the harvest of our experiment at the USDA-ARS Aquatic Weed Research Facility at Davis, California.

\section{References}

Alpert, P., 1996. Nutrient sharing in natural clonal fragments of Fragaria chiloensis. Ecology 84, 395-406.

Alpert, P., 1999a. Clonal integration of Fragaria chiloensis differs between populations: ramets from grasslands are selfish. Oecologia 120, 69-76. Alpert, P., 1999b. Effects of clonal integration on plant plasticity in Fragaria chiloensis. Plant Ecol. 141, 99-106.

Alpert, P., Holzapfel, C., Slominski, C., 2003. Differences in performance between genotypes of Fragaria chiloensis with different degrees of resource sharing. Ecology 91, 27-35.

Alpert, P., Mooney, H.A., 1986. Resource sharing among ramets in the clonal herb, Fragaria chiloensis. Oecologia 70, 227-233.

Barrat-Segretain, M.H., Bornette, G., Hering-Vilas-Bôas, A., 1998. Comparative abilities of vegetative regeneration among aquatic plants growing in disturbed habitats. Aquat. Bot. 60, 201-211.

Bornette, G., Puijalon, S., 2011. Response of aquatic plants to abiotic factors: a review. Aquat. Sci. 73, 1-14.

de Kroon, H., Hutchings, M.J., 1995. Morphological plasticity in clonal plants: the foraging concept reconsidered. Ecology 83, 143-152.

Grace, J.B., 1993. The adaptive significance of clonal reproduction in angiosperms: an aquatic perspective. Aquat. Bot. 44, 159-180.

Gratani, L., 2014. Plant phenotypic plasticity in response to environmental factors. Adv. Bot. 2014, 1-17, http://dx.doi.org/10.1155/2014/208747, Article id 208747.

Gregory, S.V., Swanson, F.J., McKee, W.A., Cummins, K.W., 1991. An ecosystem perspective of riparian zones. Bioscience 41, 540-551.

Grime, J.P., 1977. Evidence for the existence of three primary strategies in plants and its relevance to ecological and evolutionary theory. Am. Nat. 11, 1169-1194.

He, W.M., Alpert, P., Yu, F.H., Zhang, L.L., Dong, M., 2011. Reciprocal and coincident patchiness of multiple resources differentially affect benefits of clonal integration in two perennial plants. Ecology 99, 1202-1210.

Jónsdóttir, I.S., Watson, M.A., 1997. Extensive physiological integration: an adaptive trait in resource-poor environments? In: de Kroon, H., van Groenendael, J. (Eds.), The Ecology and Evolution of Clonal Plants. Backhuys, Leiden, pp. 109-136.

Loehle, C., 1987. Partitioning of reproductive effort in clonal plants: a benefit-cost model. Oikos 49, 199-208.

Méthy, M., Alpert, P., Roy, J., 1990. Effects of light quality and quantitiy on growth of the clonal plant Eichhornia crassipes. Oecologia 84, 265-271.

Okada, M., Grewell, B.J., Jasieniuk, M., 2009. Clonal spread of invasive Ludwigia hexapetala and $L$. grandiflora in freshwater wetlands in California. Aquat. Bot. 91, 123-129.

Pennings, S.C., Callaway, R.M., 2000. The advantages of clonal integration under different ecological conditions: a community-wide test. Ecology 81, 709-716.

Poorter, H., Niklas, K.J., Reich, P.B., Oleksyn, J., Poot, P., Mommer, L., 2012. Biomas allocation to leaves stems, and roots: meta-analysis of interspecific variation and control. New Phytol. 193, 30-50.

Pyšek, P., Prach, K., 1993. Plant invasions and the role of riparian habitats: a comparison of four species alien to central Europe. J. Biogeogr. 20, 413-420.

Rejmánkova, E., 1992. Ecology of creeping macrophytes with special reference to Ludwigia peploides (H.B.K.) Raven. Aquat. Bot. 43, 283-299. 
Richards, J.H., Lee, D.W., 1986. Light effects on leaf morphology in water hyacinth (Eichornia crassipes). Am. J. Bot. 73, 1741-1747.

Riis, T., Olsen, B., Clayton, J.S., Lambertini, C., Brix, H., Sorrell, B.K., 2012. Growth and morphology in relation to temperature and light availability during the establishment of three invasive aquatic plant species. Aquat. Bot. 102, 56-64.

Santamaría, L., 2002. Why are most aquatic plants widely distributed? Dispersal, clonal growth, and small-scale heterogeneity in a stressful environment. Acta Oecol. 23, 137-154.

Song, Y., Yu, F., Keser, L., Dawson, W., Fischer, M., Dong, M., van Kleunen, M., 2013. United we stand, divided we fall: a meta-analysis of experiments on clonal integration and its relationship to invasiveness. Oecologia 171, 317-327.

Spencer, D.F., Anderson, L.W.J., 1986. Photoperiod responses in monoecious and dioecious Hydrilla verticillata. Weed Sci. 34, 551-557.

Stuefer, J.F., During, H.J., de Kroon, H., 1994. High benefits of clonal integration in two stoloniferous species, in response to heterogeneous light environments. Ecology 82, 511-518.

Thompson, K., Hodgson, J.G., Rich, T., 1995. Native and alien invasive plants: more of the same? Ecography 18, 390-402.

Thouvenot, L., Haury, J., Thiébaut, G., 2013a. Seasonal plasticity of Ludwigia grandiflora under light and water depth gradients: an outdoor mesocosm experiment. Flora 208, 430-437.
Thouvenot, L., Haury, J., Thiébaut, G., 2013b. A success story: water primroses, aquatic plant pests. Aquat. Conserv. 23, 790-803.

Valladares, F., Niinemets, Ü., 2008. Shade tolerance: a key plant feature of complex nature and consequences. Annu. Rev. Ecol. Syst. 39, 237-257.

Wagner, W.L., Hoch, P.C., Raven, P.H., 2007. Revised classification of the Onagraceae. Syst. Bot. Monogr. 83, 1-222.

Wolfer, S.R., Straile, D., 2012. To share or not to share: clonal integration in a submerged macrophyte in response to light stress. Hydrobiologia 684 261-269.

Xiao, K., Yu, D., Xu, X., Xiong, W., 2007. Benefits of clonal integration between interconnected ramets of Vallisneria spiralis in heterogeneous light environments. Aquat. Bot. 86, 76-82.

Xiao, K., Yu, D., Wang, L., Han, Y., 2011. Physiological integration helps a clonal macrophyte spread into competitive environments and coexist with other species. Aquat. Bot. 95, 249-253.

Xu, C.Y., Schooler, S.S., van Klinken, R.D., 2010. Effects of clonal integration and light availability on the growth and physiology of two invasive herbs. J. Ecol 98, 833-844.

Xu, C.Y., Schooler, S.S., van Klinken, R.D., 2012. Differential influence of clonal integration on morphological and growth responses to light in two invasive herbs. PLoS One 7, 1-12. 